IRA-International Journal of Applied Sciences ISSN 2455-4499; Vol.06, Issue 01 (2017)

Institute of Research Advances

Pg. no. 15-22

http://research-advances.org/index.php/IRAJAS

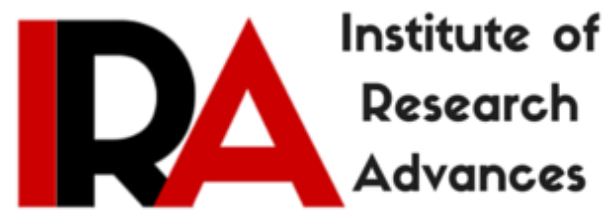

\title{
The Versatile Use of the Latissimus Dorsi Muscle Flap in Electrical Burn Injuries
}

\author{
Dr G Karthikeyan ${ }^{1}$ \\ Associate Professor \\ Dr Angeline Selvaraj ${ }^{2}$ \\ Associate Professor \\ Dr B. Rajeswari ${ }^{3}$ \\ Assistant Professor \\ ${ }^{1,2,3}$ Govt. Kilpauk Medical College Hospital, Chennai, Tamilnadu, India.
}

Type of Review: Peer Reviewed.

DOI: http://dx.doi.org/10.21013/jas.v6.n1.p3

\section{How to cite this paper:}

Karthikeyan, G., Selvaraj, A., \& Rajeswari, B. (2017). The Versatile Use of the Latissimus Dorsi Muscle Flap in Electrical Burn Injuries. IRA-International Journal of Applied Sciences (ISSN 2455-4499), 6(1), 15-22.

doi:http://dx.doi.org/10.21013/jas.v6.n1.p3

(C) Institute of Research Advances

\section{(cc) BY-No}

This work is licensed under a Creative Commons Attribution-Non Commercial 4.0 International License subject to proper citation to the publication source of the work.

Disclaimer: The scholarly papers as reviewed and published by the Institute of Research Advances (IRA) are the views and opinions of their respective authors and are not the views or opinions of the IRA. The IRA disclaims of any harm or loss caused due to the published content to any party. 


\section{Introduction}

Electricity is an indispensable part of civilization. It is often taken for granted, and can sometimes take away limbs, and at times, life. When a human being comes in contact with electricity, burns can ensue. These electrical burns are the most devastating of all thermal injuries on a size for size basis ${ }^{5}$ and involve skin and deeper tissues. 90\% of electrical injuries are accidental and nearly two-thirds occur at the work spot. Young, working males are commonly affected with frequent amputation of dominant limbs. This paper analyses the different uses of the latissimus dorsi muscle flap in the reconstruction of electrical burn raw areas and in the salvage of the amputation stumps.

\section{Discussion}

Electrical burns may occur due to low voltage or high voltage injuries. Low voltage injuries are those that occurs by an electrical current of less than 1000 volts. If the injury occurs by a current of more than 1000 volts, it is classified as high voltage injury.

\section{Low Voltage Injury}

These injuries are quite superficial, and are restricted to localised areas. An example of low voltage injury is shown below. (Figure 1)

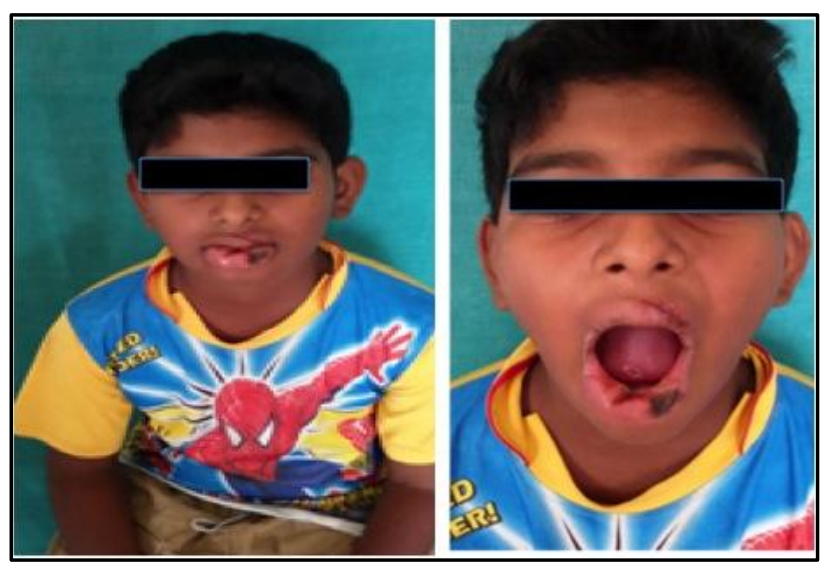

Figure 1: Low voltage electrical injury to the lower lip

\section{High Voltage Injury}

The cutaneous burn in a high voltage electrical burn is associated with deep, underlying tissue damage very closely resembling a crush injury. There are three types of burn that occur in such injuries.

a. Contact burn - that occur at the point of contact of the body with the entry and exit points of the electrical energy (Figure 2)

b. Flash burn - that occurs as a flame burn on the body of the individual, caused by the flash of fire that occurs from the electrical circuit

c. Arc burn - the burn that occurs on the flexural surfaces of the limbs, when the electrical energy enters the body through the moist areas like the elbow crease, axilla. 


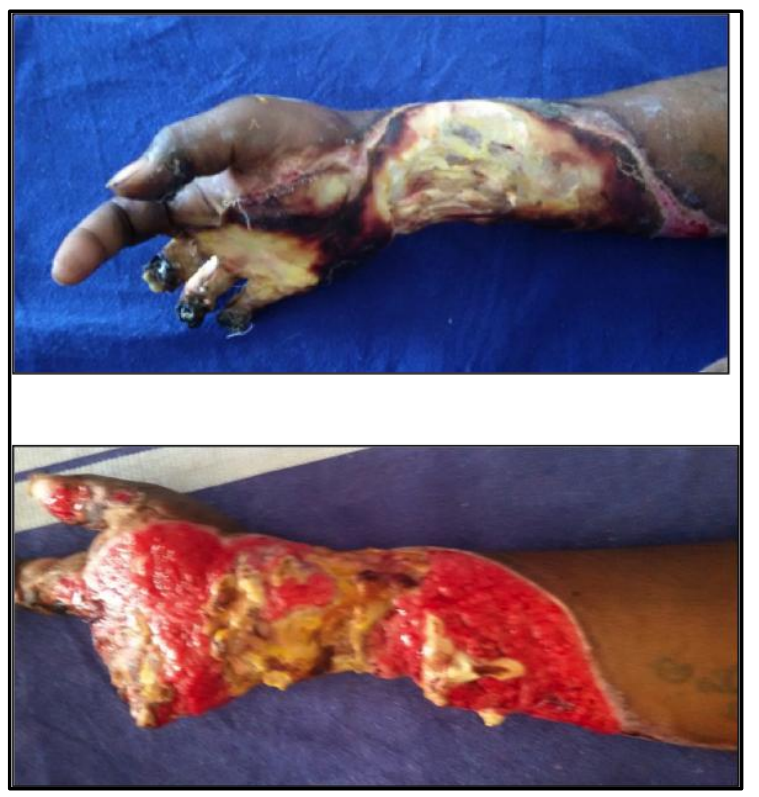

Figure 2: High voltage electrical injury to the right hand and forearm

The limbs are usually affected by the electrical burns, and all three types of burn mentioned above can occur in the limbs. As a result, the vascularity of the affected limb is compromised and gangrene ensues $^{4}$, or the wounds are deep, extending upto the bone. It is important to remember that, no injury severity score exists as a guide for severe upper-extremity trauma including electrical burns. Much of the decision making is left to the surgeon. Thus the surgeon walks in a precarious tight rope, in salvaging the whole or part of limb.

Since gangrene occurs, amputation needs to be done at appropriate levels. The amputation stump has bone, muscle, nerves and blood vessels, exposed, with little skin and soft tissues. This may result in disarticulation (Figure 3), at the level of proximal joint. And if the shoulder is involved, there will be no residual stump. If at the level of the shoulder, disarticulation is done, it will result in a stump that is useless, as no useful prosthesis can be applied.
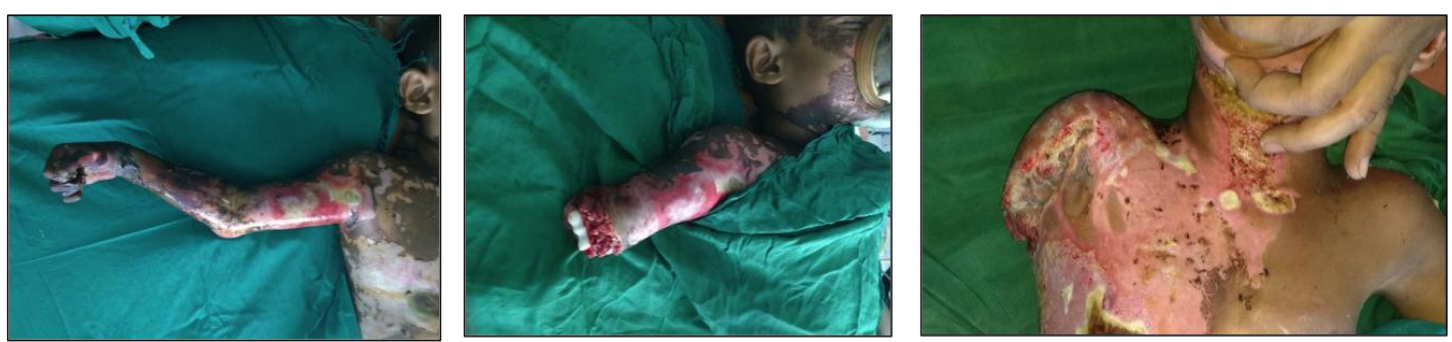

Figure 3: Progressive gangrene of right upper limb ultimately ending in shoulder disarticulation

This is because, at least a small above elbow stump should be present, and only then, a functioning prosthesis can be applied. If covered by appropriate tissue, the stump length is preserved and there by the patient enable to carry out various activities with or with out prosthesis (Figure 4)

The ideal stump should be conical, have adequate stump length, muscle padding and blood supply, to preserve adjacent joint movements. The scar should be thin, not interfering with the prosthesis. 


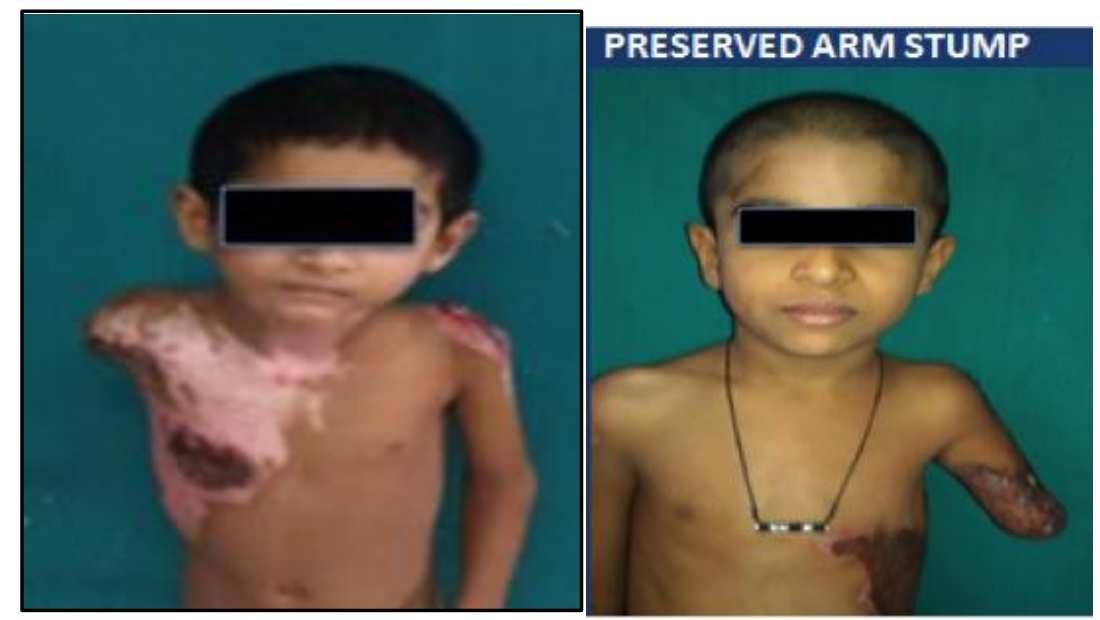

Figure 4: Need to preserve stump of arm

Generally, longer the residual stump the greater the residual function.

To preserve the stump of the arm, the latissimus dorsi muscle can be used as a cover for the length of bone $^{3}$. The latissimus dorsi can be used as a free flap ${ }^{1}$ or as a pedicled flap cover (Figure 5).

The advantage of the latissimus dorsi muscle flap is that a large volume of tissue is be available for reconstruction, a long vascular pedicle, and the possibility of harvesting large skin paddle, with minimal donor site morbidity.

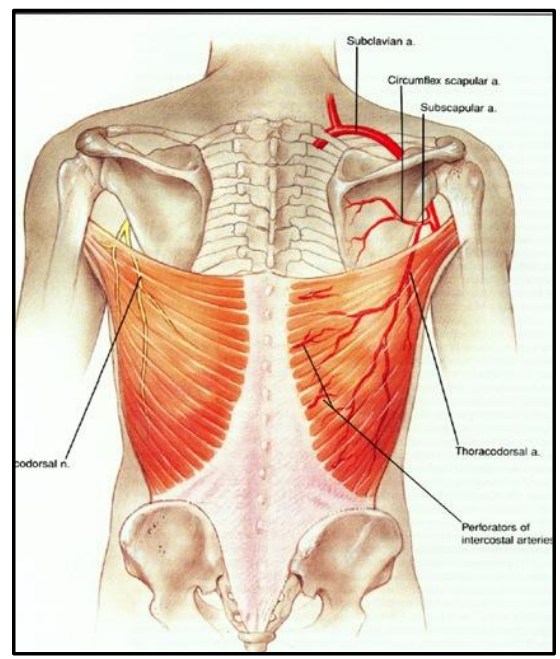

Figure 5: Vascularity of the latissimus dorsi muscle flap

\section{Materials and Methods}

At the Department of Burns, Plastic and Reconstructive surgery at Government Kilpauk Medical College, Chennai, over the period of 6 months from June 2016 to December 2016, four patients with electrical burns of the upper limb had a pedicled latissimus dorsi muscle flap for reconstruction. The LD flap was used for coverage of above elbow stumps, and also for deep wounds around the shoulder. All patients were male, in the age group of 12 to 40.

\section{Case studies}

Here are some case examples to show how the LD muscle flap is used to cover the stump, and also deep wounds around the shoulder and in the proximal aspect of the arm.

Case Study 1: A case of electrical burn raw area on the left arm, posterior aspect exposing the humerus bone with loss of radial nerve, and soft tissues. (Figure 6,7,8,9) 


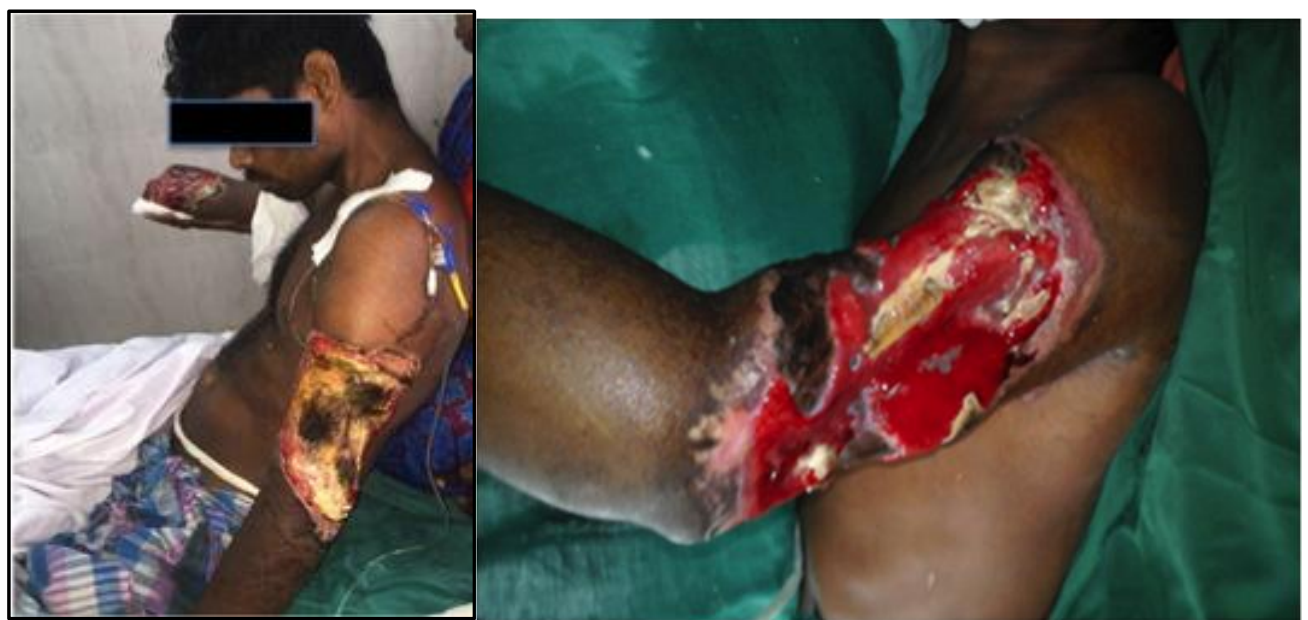

Figure 6: Raw area on the posterior and lateral aspect of left arm following electrical burns
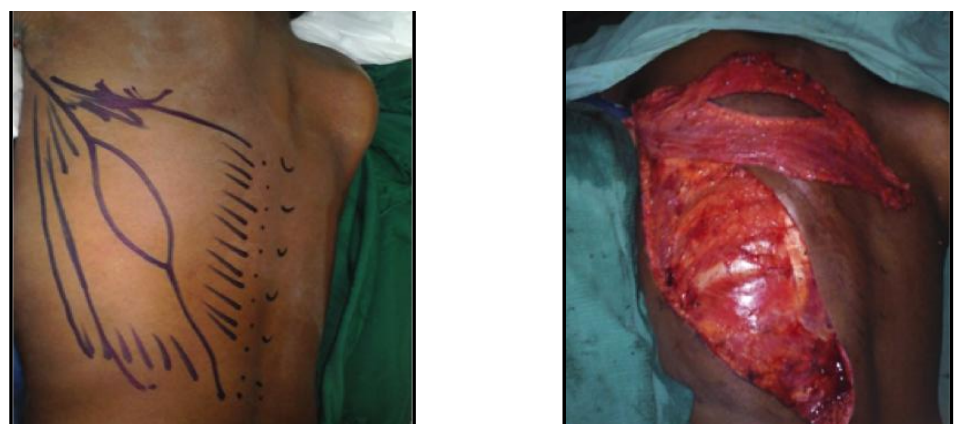

Figure 7: Markings of the LD myocutaneous flap and harvest of the flap

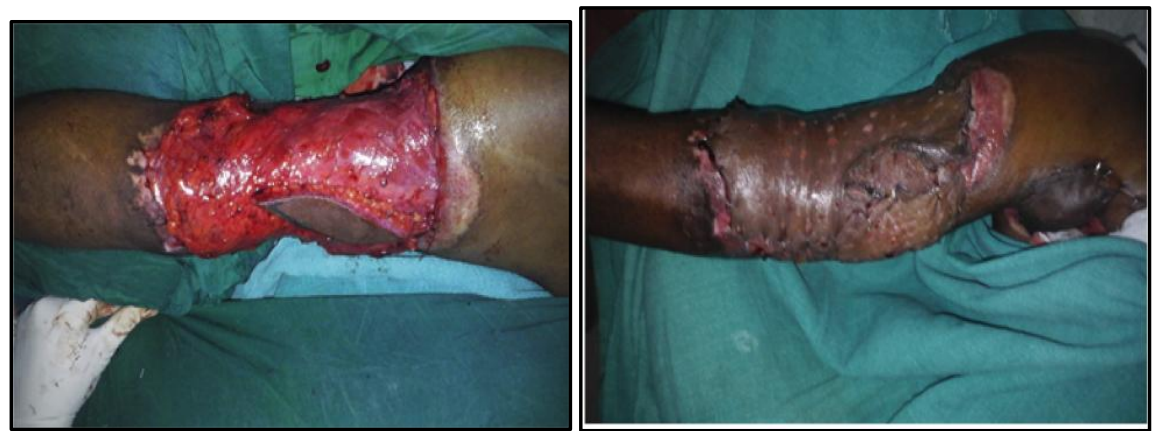

Figure 8: Inset of the muscle flap with skin graft over the muscle

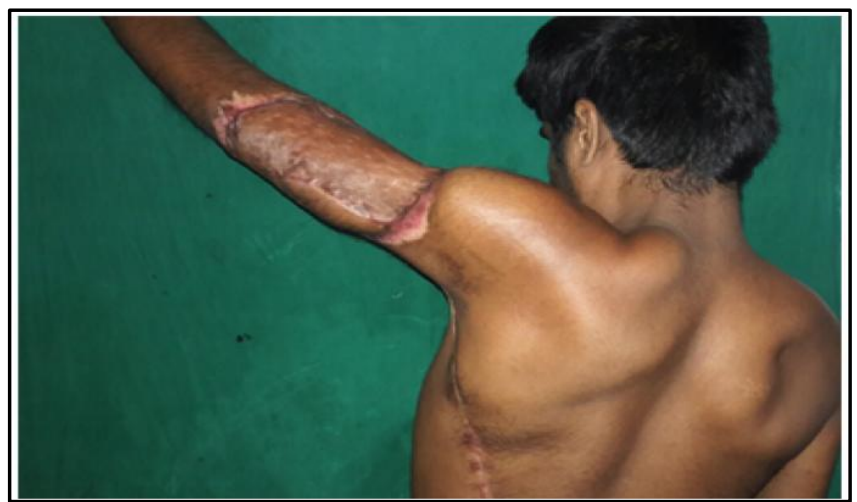

Figure 9: Late post-op result showing well settled flap and graft on the arm

Case Study 2: A case of electrical burn raw area on the left arm in a 12 year old boy, resulting in progressive gangrene, ultimately ending in an above elbow stump with humerus bone stump 
protruding. Reonstruction done by using the pedicled LD muscle for covering the stump and protecting the underlying bone. (figure 10,11)
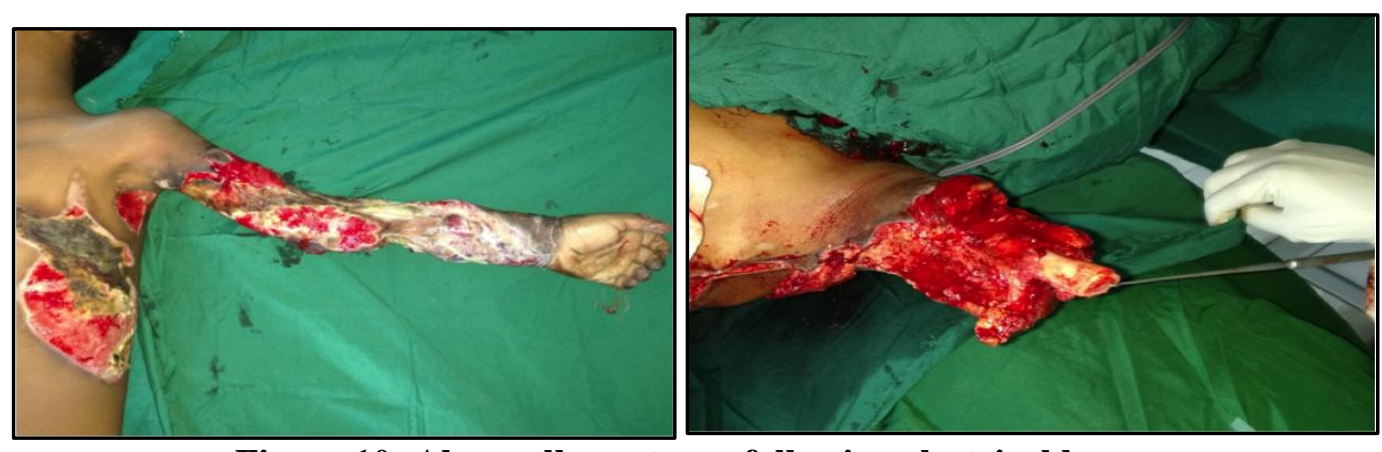

Figure 10: Above elbow stump following electrical burns
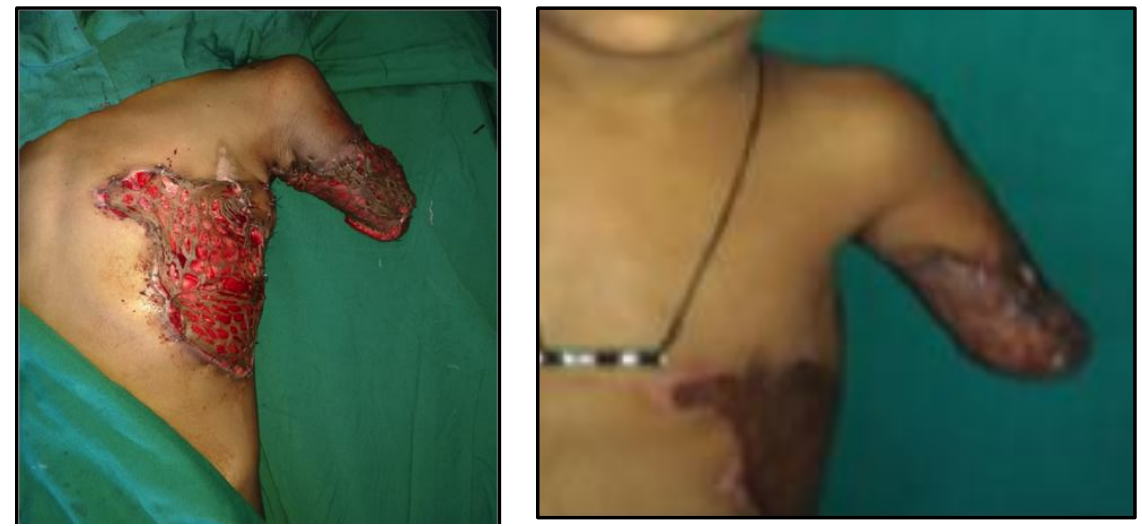

Figure 11: LD muscle flap with skin graft used to preserve the length of the stump and provide a good padding for fitting prosthesis

Case Study 3: A case of electrical burn on the right upper limb, with progressive gangrene. To preserve the above elbow stump, a pedicled LD muscle flap with skin graft was used. (Figure $12,13,14)$
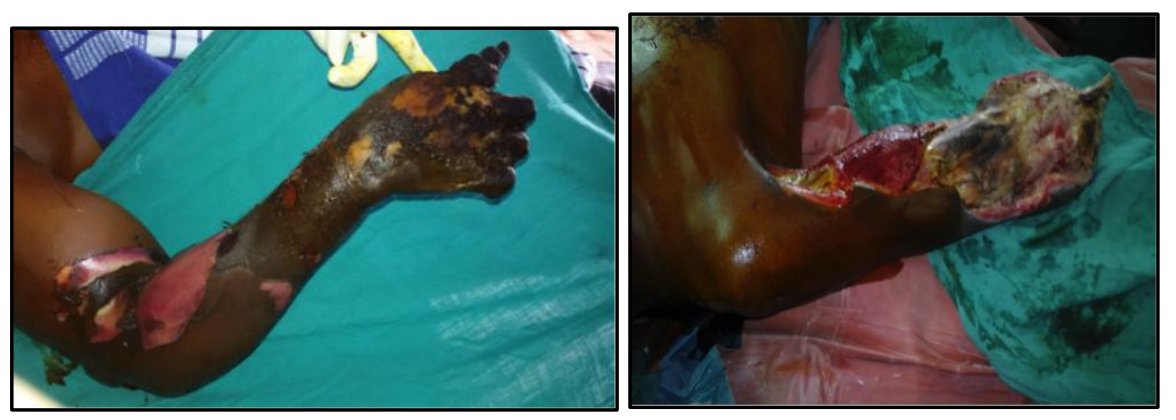

Figure 12: Progressive gangrene right upper limb following high voltage electrical burns 


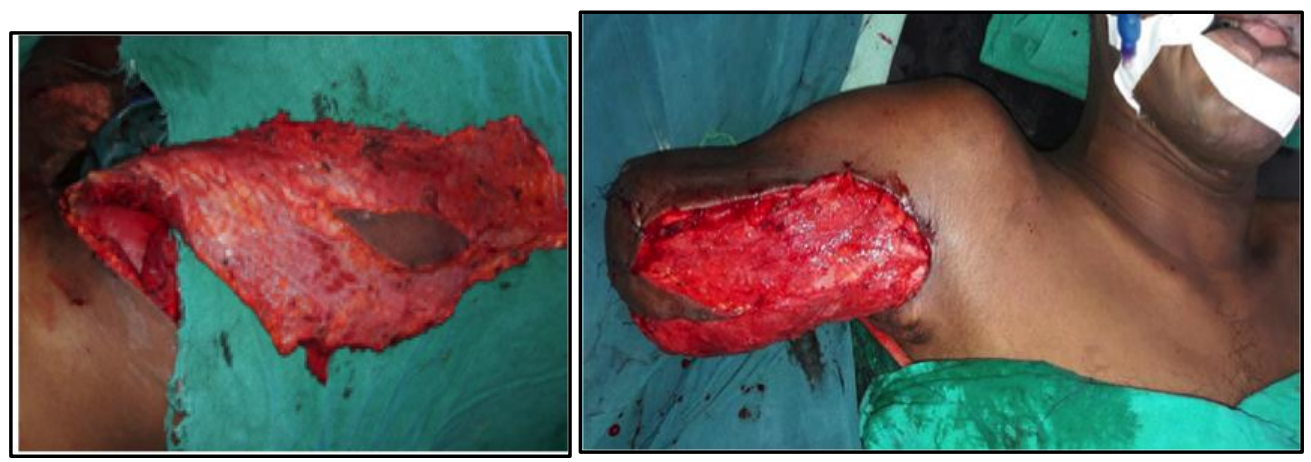

Figure 13: LD muscle harvested as a pedicled flap to cover the stump

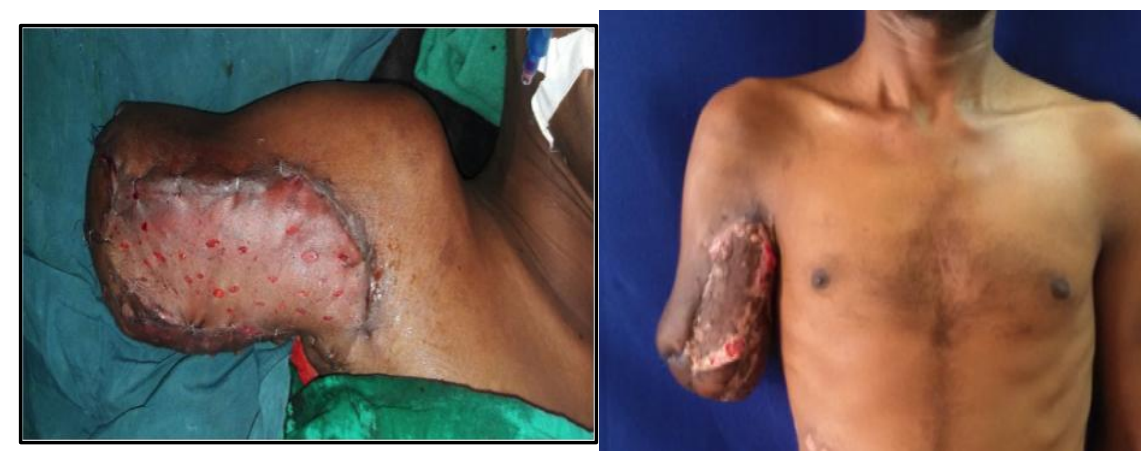

Figure 14: Well settled muscle and skin stump ready for fitting an AE prosthesis

Case study 4: A case of electrical burn on the left upper limb, with deep contact burns on the left scapular region, exposing the spine of scapula. (Figure 15)

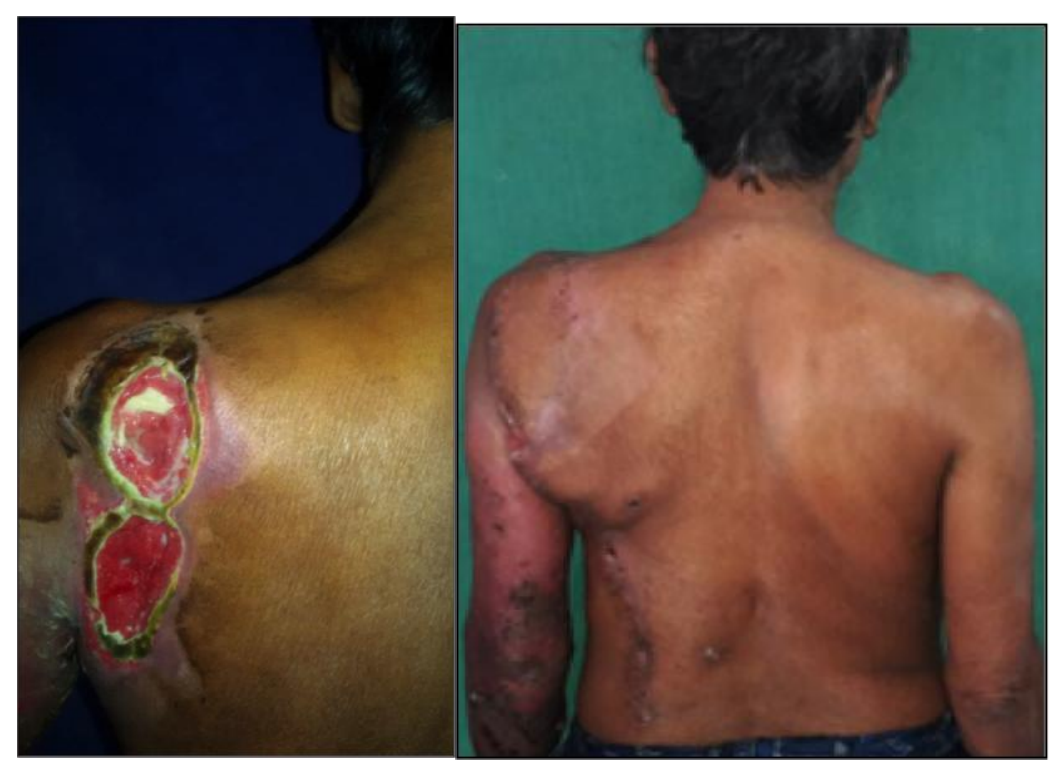

Figure 15: Deep raw area on the scapular region, exposing the spine of scapula, covered with a pedicled latissimus dorsi myocutaneous flap

\section{Conclusion}

The ipsilateral LD muscle flap is an ideal option in reconstructing upper extremity amputation stumps, and raw areas, resulting from high-voltage electrical burn injuries and that this procedure permit stump length maintenance, will permit later reconstruction, avoids extended operation times that can occur with microsurgical reconstructions, and prepares patients for prosthesis usage. 


\section{References}

1. "Maintenance of stump length of both upper extremities after severe electrical burn injury Burns" Volume 16, Issue 3, June 1990, Pages 227-229, F. Kömürcä, M. Stuffer, H. Hussl, H. Anderl

2. "Free latissimus dorsi muscle flap coverage of an electrical burn of the lower extremity", Plast Reconstr Surg. 1982 Jan;69(1):125-9. Hagan KF, Buncke HJ, Gonzalez R.

3. "Algorithms of Flap Reconstruction in High-Voltage Electrical Injuries: 26 Years Experience" Trauma Cases Rev 2015, 1:1. Cengiz Eser, Erol Kesiktas, Eyuphan Gencel, Omer Kokacya, Metin Yavuz Cukurova University Medical Faculty Plastic Reconstructive and Aesthetic Surgery, Turkey

4. "Reconstruction of a Severe Chest Electrical Burn Injury"- Case Report. Mohamed Y H Abdelrahman, Khansa Osman, Alwaleed Mohd Alamin, Ali Idris Abubakr, Military Hospital, Department of Plastic \& Reconstructive Surgery and El Ribat University Hospital. International Journal of Clinical Case Reports, 2012, Vol. 2, No. 1

5. "Aspects of reconstruction in electrical injury", Konigova R, Burns Centre, Third Medical Faculty, Charles University, Prague, Czech Republic. Annals of Burns and Fire Disasters vol. XI - n. 3 - September 1998 